Proceeding Paper

\title{
Removal of PAHs from Road Drainage System by Ultrasonication ${ }^{\dagger}$
}

\author{
Jakub Copik*, Edyta Kudlek (1) and Mariusz Dudziak
}

Citation: Copik, J.; Kudlek, E.; Dudziak, M. Removal of PAHs from Road Drainage System by Ultrasonication. Environ. Sci. Proc. 2021, 9, 4. https://doi.org/10.3390/ environsciproc2021009004

Academic Editors: Dorota Anna Krawczyk, Iwona Skoczko, Antonio Rodero Serrano and Ewa Szatyłowicz

Published: 11 October 202

Publisher's Note: MDPI stays neutral with regard to jurisdictional claims in published maps and institutional affiliations.

Copyright: (c) 2021 by the authors. Licensee MDPI, Basel, Switzerland. This article is an open access article distributed under the terms and conditions of the Creative Commons Attribution (CC BY) license (https:// creativecommons.org/licenses/by/ $4.0 /)$.
Department of Water and Wastewater Engineering, The Silesian University of Technology, Akademicka 2A, 44-100 Gliwice, Poland; edyta.kudlek@polsl.pl (E.K.); mariusz.dudziak@polsl.pl (M.D.)

* Correspondence: jakub.copik@polsl.pl

† Presented at the Innovations-Sustainability-Modernity-Openness Conference (ISMO'21), Bialystok, Poland, 14 May 2021.

\begin{abstract}
The articles reveal the removal effectiveness of 7 polycyclic aromatic hydrocarbons (PAHs), which were recognized in water from a highway drainage system by using the ultrasound treatment process. Results showed that after 45 min of sonication, the average removal of PAHs reached 59\%. The reduction of analyzed substances was proportional to treated time and irradiation amplitude. Furthermore, as a consequence of ozone addition to the sonicated samples, the efficiency of the treatment was significantly higher.
\end{abstract}

Keywords: road drainage; polycyclic aromatic hydrocarbons; PAHs; ultrasound; water treatment; advanced oxidation processes

\section{Introduction}

Polycyclic aromatic hydrocarbons (PAHs) are a group of organic compounds which consist of at least two benzene rings in angular, linear, or cluster arrangement. In most cases, they are colorless, white, or yellow solids. PAHs are characterized by high melting and boiling points, low vapor pressure, and low solubility in aqueous media. Moreover, it is generally accepted that some PAHs are cancerogenic and mutagenic [1,2]. Even though there are many described substances occurring in the environment, most regulations aim at only some of them. For instance, U.S. Environmental Protection Agency (USEPA) listed 16 PAHs according to their ecological impact and effects on human health [3]. PAHs are widely spread substances in the environment, resulting from natural and anthropogenic processes such as fires, petroleum spills, vehicles, and primarily by the incomplete combustion of the fuels. Many PAHs are also related to urban road surfaces due to vehicles and abrasion of asphalt. As a result, mentioned substances can migrate to air, water, and soil. They also have a tendency to deposit near to their source in the environment, due to low volatilization potential and high molecular weight [4].

In general, aromatics are considered as substances that are hard to remove biologically, and thus, other techniques need to be developed [5]. One which can be used in water treatment is acoustic cavitation technology, which is defined as the formation of acoustic bubbles due to ultrasound, and their subsequent collapse in given conditions. During the collapse of the bubbles, pollutants can be eliminated by the mechanical effects, oxidation, and occurrence of high pressure and temperature conditions [6,7]. This study aims to determine PAHs in the samples from one of the highway rainwater drainage systems, and evaluate the impact of ultrasound treatment on the removal of PAHs from the treated samples. Furthermore, this work examines the effect of ozone treatment assisted with ultrasonication on the above-mentioned substances' elimination efficiency. 


\section{Materials and Methods}

To determine the PAHs in the sample collected from the highway drainage system, and to evaluate their removal efficiency, a gas chromatograph (7890B, Perlan Technologies, Warsaw, Poland) has been used. To improve the quality of the analysis, the samples were prepared as described by Bohdziewicz et al. [8] using the solid phase extraction (SPE) method applying Supelclean ${ }^{\mathrm{TM}} \mathrm{ENVI}^{\mathrm{TM}}-18$ cartridges, which were supplied by SigmaAldrich. The collected sample was tested for basic parameters and indicators, including $\mathrm{pH}$, conductivity, turbidity, and color. After a $1 \mathrm{mgL}^{-1}$ dosage previously identified in the water PAHs, the samples were treated by ultrasonic processor Sonics VCX 500 (Vibra Cell Sonics and Materials, USA), characterized by the frequency of $20 \mathrm{kHz}$ and a $13 \mathrm{~mm}$ diameter probe. In the experiments, the irradiation amplitude (during 1 min sonication) and irradiation time (at $114 \mu \mathrm{m}$ amplitude) effect of PAHs' removal efficiency was evaluated. The volumes of the treated sample were 50 and $100 \mathrm{~cm}^{3}$, respectively. At the last stage of the study, $100 \mathrm{~cm}^{3}$ of water, during $1 \mathrm{~min}$ ultrasound treatment at the $114 \mu \mathrm{m}$ amplitude, was assisted by $1,3,5$, and $10 \mathrm{mgL}^{-1}$ ozone addition. In this work, ozoner FM500 (WRC Multiozone, Gdansk, Poland) was used.

\section{Results and Discussion}

A chromatographic analysis revealed that, in the collected sample, 7 of the PAHs were present, namely naphthalene, acenaphthylene, fluorene, phenanthrene, fluoranthene, pyrene, and benzo[k]fluoranthene (Table 1). Notably, benzo[k]fluoranthene was classified by International Agency for Research on Cancer (IARC) as a substance possibly cancerogenic for humans. The other measured parameters of collected water quality, which might indicate the presence of harmful substances, were conductivity $(204.5 \mu \mathrm{m} / \mathrm{cm}), \mathrm{pH}(7.80)$, turbidity (26.2 NTU), and color (242 $\left.\mathrm{mg} \mathrm{Pt} \mathrm{L}^{-1}\right)$.

Table 1. The chemical characteristic of PAHs identified in the water [9].

\begin{tabular}{cccc}
\hline Name & Molecular Formula & Molecular Mass (gmol $^{-\mathbf{1}}$ ) & CAS No. \\
\hline Naphthalene & $\mathrm{C}_{10} \mathrm{H}_{8}$ & 128.17 & $91-20-3$ \\
Acenaphthylene & $\mathrm{C}_{12} \mathrm{H}_{8}$ & 152.19 & $208-96-8$ \\
Fluorene & $\mathrm{C}_{13} \mathrm{H}_{10}$ & 166.22 & $86-73-7$ \\
Phenanthrene & $\mathrm{C}_{14} \mathrm{H}_{10}$ & 178.23 & $85-01-8$ \\
Fluoranthene & $\mathrm{C}_{16} \mathrm{H}_{10}$ & 202.25 & $206-44-0$ \\
Pyrene & $\mathrm{C}_{6} \mathrm{H}_{10}$ & 202.25 & $129-00-0$ \\
Benzo[k]fluoranthene & $\mathrm{C}_{20} \mathrm{H}_{12}$ & 252.30 & $207-08-9$ \\
\hline
\end{tabular}

In the ultrasonic treatment of the samples, $23,68,91$, and $114 \mu \mathrm{m}$ of amplitude were used, and it was observed that increasing amplitude results in a higher degradation degree of PAHs, which could be explained by the occurrence of higher intensity, and at the same time, hydroxyl radicals generation. At the maximum amplitude, average removal efficiency reached $76 \%$, thus, an amplitude of $114 \mu \mathrm{m}$ was used in further experiments.

The effect of irradiation time on PAHs degradation rate was explored for 1, 5, 15, 30, and $45 \mathrm{~min}$. As a result, the average reductions of PAHs were respectively 18, 32, 45, 54, $59 \%$, and the highest efficiency after $45 \mathrm{~min}$ was obtained in the case of phenanthrene and the lowest in case of pyrene, which could be caused by their internal structure properties.

At the last stage of the experiment, 1, 5, and $10 \mathrm{mg} \mathrm{L}^{-1}$ of ozone were used. The removal efficiency of PAHs was explored in ozonation as a single process, and ozonation assisted with ultrasonic treatment. It can be concluded that the maximum average degradation degree of all identified PAHs was obtained during combined $\mathrm{O}_{3}$ treatment at maximum concentration and ultrasonication (removal of $96 \%$ ). Ozonation used as a single process resulted in $73 \%$ maximum PAHs degradation at the dosage of $10 \mathrm{mg} \mathrm{L}^{-1}$. Both ozonation used alone and with ultrasound treatment assistance was more efficient than $1 \mathrm{~min}$ ultrasonication as a single process (removal of $18 \%$ ). However, in every case, 
the ultrasonic assistance of the ozonation process led to a much higher decomposition rate of PAHs.

\section{Conclusions}

To sum up, PAHs can enter the environment as a result of many anthropogenic and natural processes. Due to their unfavorable health effects on humans, it is necessary to eliminate them from aqueous systems. In the sample collected from highway drainage, naphthalene, acenaphthylene, fluorene, phenanthrene, fluoranthene, pyrene, and benzo[k]fluoranthene were identified. Overall, preformed experiments indicate that ultrasound treatment had a high efficiency when it comes to PAHs' removal, especially when it is combined with the ozonation process. The degradation degree of PAHs was proportional to the irradiation amplitude, time, and $\mathrm{O}_{3}$ dosage. Maximum average reduction $(96 \%)$ was obtained by the addition of $10 \mathrm{mg} \mathrm{L}^{-1} \mathrm{O}_{3}$ combined with ultrasound treatment.

Author Contributions: J.C., E.K. and M.D. conceived and designed the experiments; J.C. and E.K. performed the experiments and analyzed data under the supervision of M.D.; J.C. wrote the paper under the supervision of E.K. and M.D. All authors have read and agreed to the published version of the manuscript.

Institutional Review Board Statement: Not applicable.

Informed Consent Statement: Not applicable.

Acknowledgments: This work was supported by Ministry of Science and Higher Education Republic of Poland within statutory funds, 2021.

Conflicts of Interest: The authors declare no conflict of interest.

\section{References}

1. Abdel-Shafy, H.I.; Mansour, M.S.M. A Review on Polycyclic Aromatic Hydrocarbons: Source, Environmental Impact, Effect on Human Health and Remediation. Egypt. J. Pet. 2016, 25, 107-123. [CrossRef]

2. IARC. Chemical Agents and Related Occupations; International Agency for Research on Cancer: Lyon, France, 2012; Volume 100, pp. 5-592.

3. USEPA. Polycyclic Aromatic Hydrocarbons (PAHs); United States Environmental Protection Agency: Washington, DC, USA, 2008.

4. Gbeddy, G.; Goonetilleke, A.; Ayoko, G.A.; Egodawatta, P. Transformation and Degradation of Polycyclic Aromatic Hydrocarbons (PAHs) in Urban Road Surfaces: Influential Factors, Implications and Recommendations. Environ. Pollut. 2020, 257, 113510. [CrossRef] [PubMed]

5. Gupta, P.; Suresh, S.; Jha, J.M.; Banat, F.; Sillanpää, M. Sonochemical Degradation of Polycyclic Aromatic Hydrocarbons: A Review. Environ. Chem. Lett. 2021, 19, 2663-2687. [CrossRef]

6. Doosti, M.R.; Kargar, R.; Sayadi, M.H. Water Treatment Using Ultrasonic Assistance: A Review. Ecology 2012, 2, 96-110.

7. Wu, P.; Bai, L.; Lin, W.; Wang, X. Mechanism and Dynamics of Hydrodynamic-Acoustic Cavitation (HAC). Ultrason. Sonochem. 2018, 49, 89-96. [CrossRef] [PubMed]

8. Bohdziewicz, J.; Dudziak, M.; Kamińska, G.; Kudlek, E. Chromatographic Determination and Toxicological Potential Evaluation of Selected Micropollutants in Aquatic Environment-Analytical Problems. Desalin. Water Treat. 2016, 57, 1361-1369. [CrossRef]

9. Kim, S.; Thiessen, P.A.; Bolton, E.E.; Chen, J.; Fu, G.; Gindulyte, A.; Han, L.; He, J.; He, S.; Shoemaker, B.A.; et al. PubChem Substance and Compound Databases. Nucleic Acids Res. 2016, 44, D1202-D1213. [CrossRef] [PubMed] 